\title{
Evaluation on the Mechanical Performance of Low-Quality Recycled Aggregate Through Interface Enhancement Between Cement Matrix and Coarse Aggregate by Surface Modification Technology
}

\author{
Heesup Choi ${ }^{1)}$, Hyeonggil Choi ${ }^{2), *}$, Myungkwan Lim $^{3)}$, Masumi Inoue ${ }^{1)}$, Ryoma Kitagaki ${ }^{4}$, \\ and Takafumi Noguchi ${ }^{4)}$
}

(Received September 1, 2015, Accepted December 20, 2015, Published online January 20, 2016)

\begin{abstract}
In this study, a quantitative review was performed on the mechanical performance, permeation resistance of concrete, and durability of surface-modified coarse aggregates (SMCA) produced using low-quality recycled coarse aggregates, the surface of which was modified using a fine inorganic powder. The shear bond strength was first measured experimentally and the interface between the SMCA and the cement matrix was observed with field-emission scanning electron microscopy. The results showed that a reinforcement of the interfacial transition zone (ITZ), a weak part of the concrete, by coating the surface of the original coarse aggregate with surface-modification material, can help suppress the occurrence of microcracks and improve the mechanical performance of the aggregate. Also, the use of low-quality recycled coarse aggregates, the surfaces of which were modified using inorganic materials, resulted in improved strength, permeability, and durability of concrete. These results are thought to be due to the enhanced adhesion between the recycled coarse aggregates and the cement matrix, which resulted from the improved ITZ in the interface between a coarse aggregate and the cement matrix.
\end{abstract}

Keywords: surface-modification technology, interfacial transition zone (ITZ), low-quality recycled coarse aggregate, interface strength, durability, micro-crack.

\section{Introduction}

Concrete is one of the most prominent materials used for construction in modern societies. Among its constituents, aggregates for concrete have a significant impact on quality of the density and water absorption ratios as they account for $70-80 \%$ of the total volume (Choi et al. 2014a; Noguchi and Tamura 2001). Thus, in order to manufacture high-quality concrete, there is a need to use quality aggregates with stable physical and chemical properties (Choi et al. 2014a). Figure 1 shows the estimated volume of concrete waste and demand for aggregates in Japan from 1950 to 2100. There has been a decrease in the total aggregate market and the demand for aggregates for concrete mixes, and the service life of concrete structures built in the 1970s is running out. These factors contribute to the increased deconstruction of concrete structures and generation of recycled aggregates

\footnotetext{
${ }^{1)}$ Kitami Institute of Technology, Kitami, Japan.

${ }^{2)}$ Muroran Institute of Technology, Muroran, Japan.

*Corresponding Author;

E-mail: chg810@mmm.muroran-it.ac.jp

${ }^{3}$ Hankyong National University, Anseong, Korea.

${ }^{4)}$ The University of Tokyo, Tokyo, Japan.

Copyright ( $\odot$ The Author(s) 2016. This article is published with open access at Springerlink.com
}

(Noguchi 2008). Recycled aggregates are mainly used as a sub-base course material, and the recycling rate has been fairly high. In the long term, however, as the demand for subbase course materials is expected to fall because of declining road construction (Hendriks and Janssen 2001; Shima et al. 2005), it is important to expand the scope of concrete-waste recycling and use recycled aggregates for concrete mixes. In an effort to resolve these issues, the Japanese Industrial Standards (JIS), formed to establish the standards used for industrial activities in Japan, amended the standards for recycled aggregates in order to expand the distribution of recycled aggregates generated from concrete waste in Japan, and there have been advances in the recycling system for concrete (Choi et al. 2012). However, low-quality recycled aggregates manufactured by simple processing is a major cause of reduced concrete performance, and low quality is recognized as a factor that hinders the expanded use of recycled aggregates. Therefore, it is important to improve the interface between cement matrix and coarse aggregate of low-quality recycled aggregates to promote their application in concrete mixes. Qualitative improvement will in turn enhance the mechanical performance such as the modulus of elasticity and strength, and it will be possible to manufacture concrete with improved durability in terms of drying shrinkage, neutralization, and freezing-thawing. Choi et al. (2014a, b) conducted a study on surface modification (Noguchi and Tamura 2001; Tsujino et al. 2010, 2011) 
through the use of an inorganic material on crushed stone aggregates; they reported its effect on improving the mechanical characteristics of crushed stone aggregates and recovering high-quality recycled aggregates. Of particular note, based on the method using sand enveloped by cement (SEC), in which fine aggregates are coated with a cement paste with low water-to-cement $(\mathrm{W} / \mathrm{C})$ ratio, while the mixing water is added in steps (Tazawa 2002), a surface-modification technique was developed for the enhancement of concrete performance by improving the interfacial transition zone (ITZ), which is the weak region in concrete (Tsujino et al. 2007; Choi et al. 2014b).

In this study, crushed-stone coarse aggregates, whose surfaces had been modified, were used to fabricate the concrete specimens. The bonding performance was assessed and the interface was observed with microscopy. The resulting improvement in the concrete's mechanical

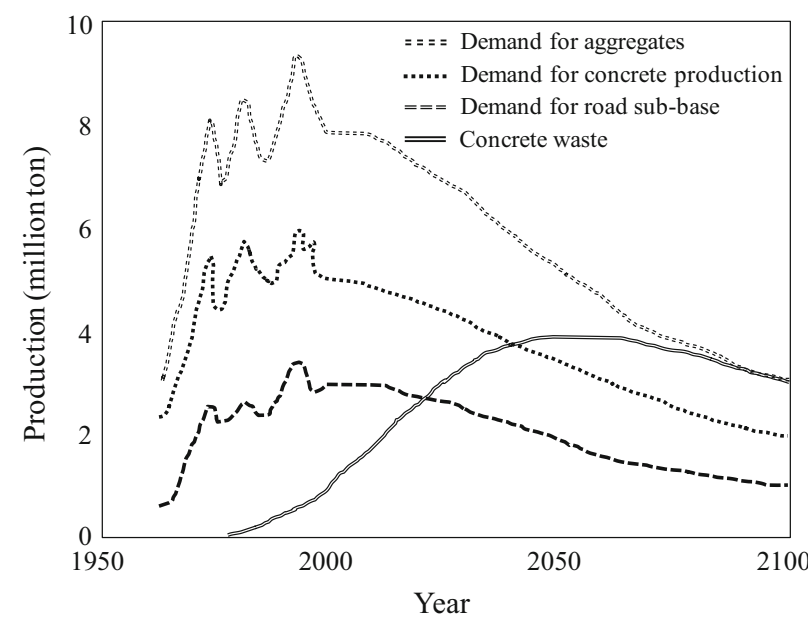

Fig. 1 Estimation of concrete waste and aggregate demand in Japan (Noguchi and Tamura 2001). performance and the applicability of the surface-modification technology to low-quality recycled aggregates with low density and large water absorption ratio was determined. Moreover, the effects of surface modification on low-quality recycled aggregates, which are mainly used as a sub-base course material, were examined, and their effects on the mechanical and permeation resistance of the water and deterioration factor into the concrete and durability performance of concrete were reviewed.

\section{Surface-Modification Technology}

In general, the factors that determine the mechanical performance of concrete are the strength of the cement matrix, strength of aggregates (which is sufficiently high in most cases), strength of the interface between an aggregate and the cement matrix (which is the source of weakness in most cases), and stress acting on the interface (related to the ratio between the elastic modulus of the cement matrix and the elastic modulus of the aggregate). Another factor that has been reported to have a significant impact on the physical properties and durability of general concrete is the ITZ between an aggregate and the cement paste. This is a particularly weak area of concrete that consists of pores around the hydrates and aggregate and is characterized by a discontinuous and porous area between the aggregate and cement paste (Kumar Mehta and Moneiro 2006). Thus, it is reasoned that the strength of concrete can be improved to a certain extent by increasing the strength of the interface when the $\mathrm{W} / \mathrm{C}$ ratio of the cement matrix is kept the same. The surface-modification technique makes it possible to improve the mechanical frictional force and chemical bond between each aggregate and the cement matrix by coating the surface of the original aggregates with cement paste

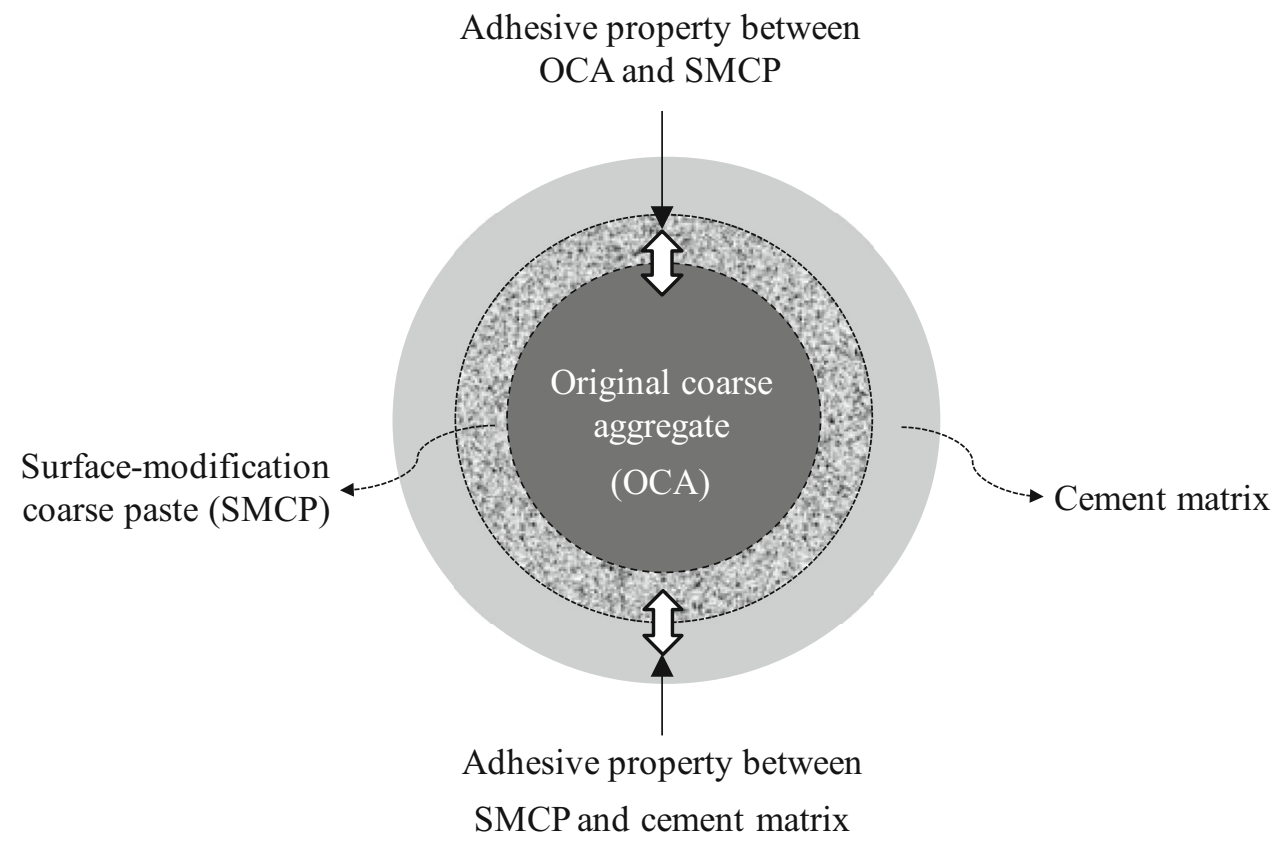

Fig. 2 Surface adhesion of modified aggregate (Choi et al. 2014a). 
using an inorganic material, thereby improving the ITZ and enhancing the mechanical characteristics of the resulting concrete (Tsujino et al. 2007, 2010, 2011; Choi et al. 2014b). Figure 2 shows a schematic diagram of the bonding mechanism at each interface after surface modification, while Fig. 3 shows the dominant factors in the adhesion of the components at each interface after the addition of a surface modifier (modification paste) (Choi et al. 2014a, b). The resulting concrete consists of the three main components, defined as follows: original coarse aggregate (OCA); coating material of OCA surface (surface-modification coarse paste) (SMCP); surface-modified coarse aggregate (SMCA); lowquality recycled coarse aggregate (LRCA).

\section{Effects of Surface Modification on the Mechanical Characteristics of Each Interface}

\subsection{Overview of the Experiment}

An assessment was conducted on the bond, i.e., integrity, between the original aggregate and the modification paste, as well as the bond between the modification paste and the cement matrix, using the surface-modification technique mentioned in Sect. 2. In order to assess the chemical and physical bonds of the modified aggregate, general aggregates, and the cement matrix, specimens simulating coarse aggregates, modification paste, and mortar were fabricated as shown in Fig. 4, based on the modification paste and mortar mix reported in an earlier study on surface modification (Choi et al. 2014b). Compressive- and tensile-shear bonding tests were performed to assess the effect of surface modification on the chemical and physical bonding characteristics of the aggregate and cement matrix. In addition, samples were collected from each of the specimens, on which the compressive-shear bonding test was performed, for observation with field-emission scanning electron microscopy (FE-SEM) to microscopically analyze the bonding performance of each interface. It should be noted, however, that the coarse aggregates used in this experiment were general crushed stone aggregates that were cut. Based on the results of the experiment, the applicability of the surface-modification technology on low-quality recycled aggregates was determined.

\subsection{Experimental Method}

In this experiment, crushed hard sandstone (density in saturated surface-dry condition: $2.66 \mathrm{~g} / \mathrm{cm}^{3}$; water absorption ratio: $0.70 \%$ ) that was cut was used as coarse aggregates (Choi et al. 2012). The objective was to assess the mechanical performance of concrete that contained aggregates, the adhesion quality of which was improved by coating the surface of the original aggregates with an inorganic powder (Table 1). Here, the $\mathrm{W} / \mathrm{C}$ ratio of mortar was $55 \%$, and this was true for all of the specimens (Table 2). The dimensions of the specimens for the compressive- and tensile-shear bonding tests were $10 \times 10 \times 40(\mathrm{~cm})$ and $10 \times 10 \times 20(\mathrm{~cm})$, respectively. Also, in order to vary the magnitude of stress on the bonding interface in the compressive- and tensile-shear bonding tests, fabricated modified aggregates cut to have an interface angle of $30^{\circ}, 45^{\circ}$, and $60^{\circ}$ were added to the formwork and mortar was added afterwards. After the surface of the original aggregates was coated with the surface-modification paste, they were aircured for 28 days at a constant temperature of $20{ }^{\circ} \mathrm{C}$ and a humidity level of $60 \% \mathrm{RH}$ prior to the mortar placement. Next, to prevent failure in the aggregate-mortar-matrix

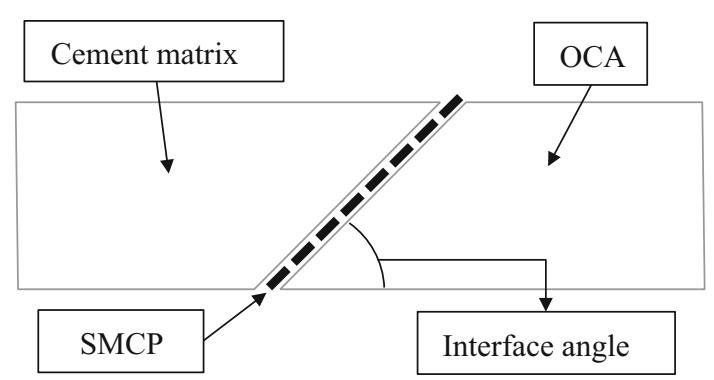

Fig. 4 Specimen for shear bonding test of SMCA concrete (Tsujino et al. 2010).

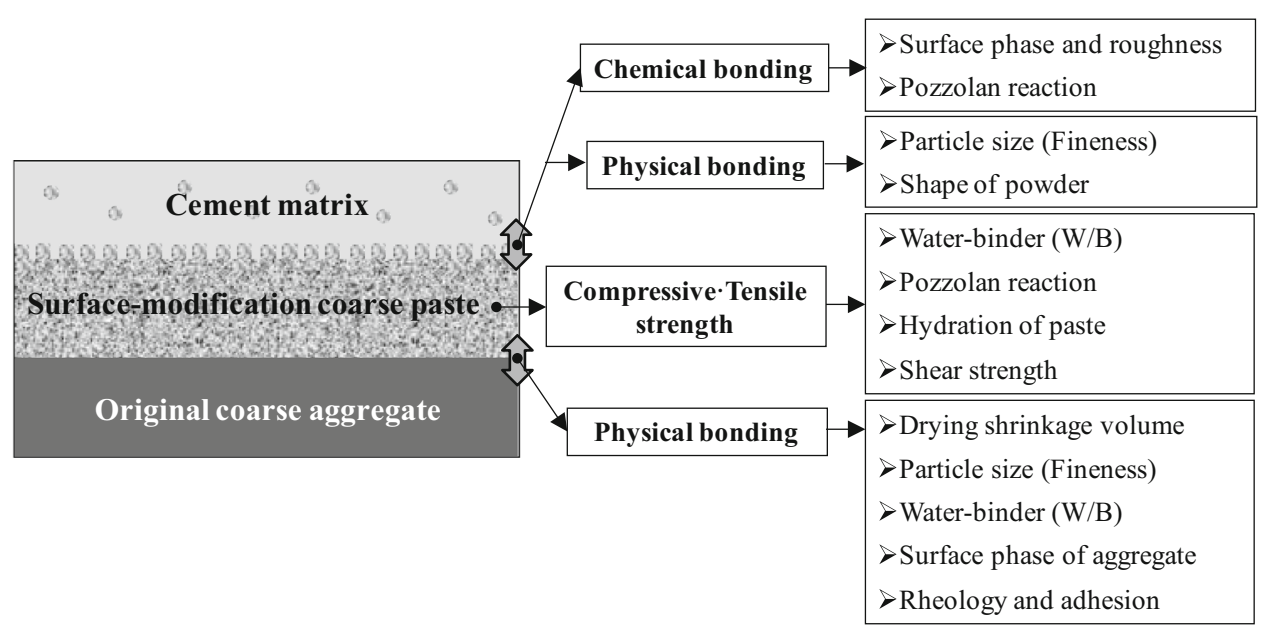

Fig. 3 Dominant factor in surface adhesion of a modified aggregate (Choi et al. 2014a). 
Table 1 Composition of SMCP.

\begin{tabular}{c|c|c|c|c}
\hline \multirow{2}{*}{ W/C (\%) } & \multirow{2}{*}{$\mathrm{W}(\mathrm{mL})$} & \multicolumn{2}{|c}{$\mathrm{C}$} & \multirow{2}{*}{$\mathrm{Fe}_{2} \mathrm{O}_{3}(\%)$} \\
\cline { 3 - 5 } & & Volume $(\mathrm{mL} / \mathrm{L})$ & Weight $(\mathrm{g} / \mathrm{L})$ & \\
\hline \hline 30 & 487 & 513 & 1620 & $\mathrm{C} \times 100$ \\
\hline
\end{tabular}

$W$ water, $C$ cement: density of cement: $3.16 \mathrm{~g} / \mathrm{cm}^{3}$.

Table 2 Composition of mortar.

\begin{tabular}{c|c|c|c|c|c|c}
\hline \multirow{2}{*}{ Type } & W/C (\%) & Air (\%) & \multicolumn{4}{|c}{ Unit weight $\left(\mathrm{kg} / \mathrm{m}^{3}\right)$} \\
\cline { 4 - 7 } & & & $\mathrm{W}$ & $\mathrm{C}$ & Fine aggregate & Admixture \\
\hline \hline $\mathrm{O}$ & 55 & $4.5 \pm 1.5$ & 175 & 318 & 833 & $1.59\left(\mathrm{a}^{*}\right)$ \\
\hline $\mathrm{M}$ & & & & & & \\
\hline
\end{tabular}

$O$ OCA concrete, $M$ SMCA concrete; $a^{*}$ air entraining agent.

interface, air curing was performed for 5 days at a constant temperature of $20{ }^{\circ} \mathrm{C}$ and a humidity level of $60 \% \mathrm{RH}$, and water curing was performed for 28 days at $20^{\circ} \mathrm{C}$. The bonding failure load was then measured at a loading speed of $1 \mathrm{~mm} / \mathrm{min}$. In the tensile-shear bonding test, an epoxy adhesive was used on the tension test device to perform the loading using a ring without causing eccentricity (Choi et al. 2014b). Moreover, for a more quantitative examination of the mechanism in which the strength of modified aggregates is improved, through a microscopic analysis of the ITZ, the specimens shown in Fig. 5 were formed in such a way to allow high-magnification FE-SEM observation using the device shown in Fig. 6. Table 3 is a summary of the experimental factors and conditions, and Table 4 presents the experimental levels of the SMCA concrete.

\subsection{Compressive- and Tensile-Shear Bond}

Figure 7 shows the results of the compressive- and tensileshear bonding experiments. First, the compressive-shear bond strength of the modified aggregate (M-C) was about $50 \%$ higher than that of a general aggregate $(\mathrm{O})$, regardless of the interface angle. Also, there was a negative correlation between the interface angle of the modified aggregate and the compressive-shear bond strength, which is considered to be due to the sliding effect at higher interface angles, regardless of the area of the bond. Meanwhile, the tensile-

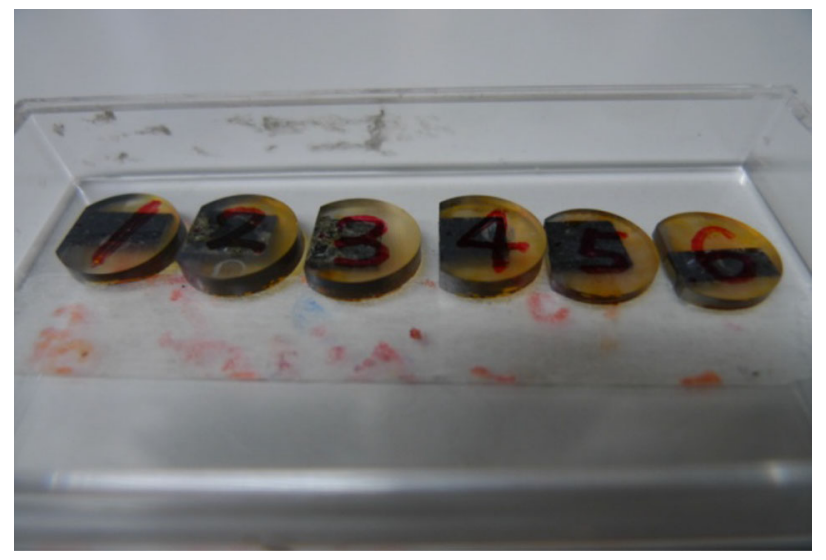

Fig. 5 Specimens for FE-SEM. shear bond strength of the SMCA tended to increase with increasing interface angle. It is considered that the tensile strength was improved by the modification since a larger area of bonding meant larger area of improvement in the ITZ.

\subsection{Microscopic Observation of the Interface Between Each Aggregate and the Cement Matrix}

Generally, failure in concrete caused by loading starts in the ITZ between the aggregate and the cement paste (Um and Choi 1997). Figures 8 and 9 show the interfacial characteristics of general (OCA) and modified aggregates (SMCA), determined based on FE-SEM observations. In the case of the OCA, a crack was formed in the interface, as shown at $\times 1,000$ magnification in Fig. 8 a, exposing the interface between the original aggregate and the cement matrix. Figure $8 \mathrm{~b}$ shows the area of the cement matrix in the general-aggregate concrete, where the original aggregate had become detached. An arbitrary observation point within the general ITZ (about 10-50 $\mu \mathrm{m}$ ) (Kumar Mehta and Moneiro 2006) was designated, and the hydration products in this area were observed, as shown in Fig. 8c and d. A large amount of calcium hydrate $\left(\mathrm{Ca}(\mathrm{OH})_{2}\right)$, which causes weakening of concrete strength, was found in the ITZ, and it is considered to be the cause of microcracks in the ITZ and the reduced strength. On the other hand, in the case of the SMCA, no cracks were observed in the interface between the

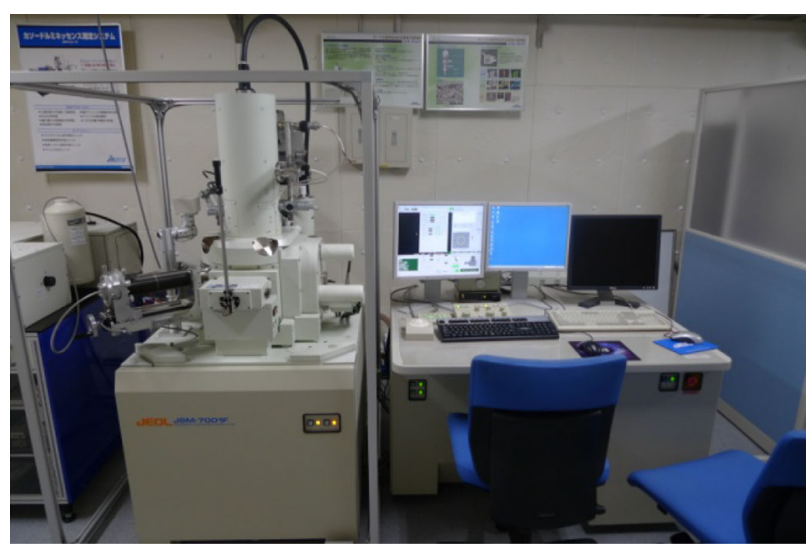

Fig. 6 FE-SEM setup.

90 | International Journal of Concrete Structures and Materials (Vol.10, No.1, March 2016) 
Table 3 Experimental factors and conditions.

\begin{tabular}{c|c|c}
\hline \multicolumn{2}{c|}{ Experimental factors } & Conditions \\
\hline \hline \multicolumn{2}{c|}{ OCA } & $\begin{array}{c}\text { Cutting specimen of crushed hard sandstone } \\
\text { (standard density: } 2.66 \mathrm{~g} / \mathrm{cm}^{3} ; \text { water } \\
\text { absorption ratio: } 0.70 \%)\end{array}$ \\
\hline SMCP & W/C & $30 \%$ \\
\hline \multicolumn{2}{c|}{ Modification } & Cement \\
\hline \multicolumn{2}{l}{ Cement matrix } & Normal strength, W/C $=55 \%$ \\
\hline
\end{tabular}

Table 4 Experimental levels.

\begin{tabular}{c|c|c|c}
\hline Experiment & Modification paste & Compressive-shear test & Tensile-shear test \\
\hline \hline $\mathrm{O}$ & $\mathrm{N} / \mathrm{A}$ & $\mathrm{P}$ & $\mathrm{P}$ \\
\hline $\mathrm{M}-\mathrm{C}$ & $\mathrm{A}$ & & \\
\hline
\end{tabular}

$O$ original coarse aggregate (OCA), $M$ surface-modified coarse aggregate (SMCA), $C$ cement, $N / A$ not applicable, $A$ applied, $P$ performed.

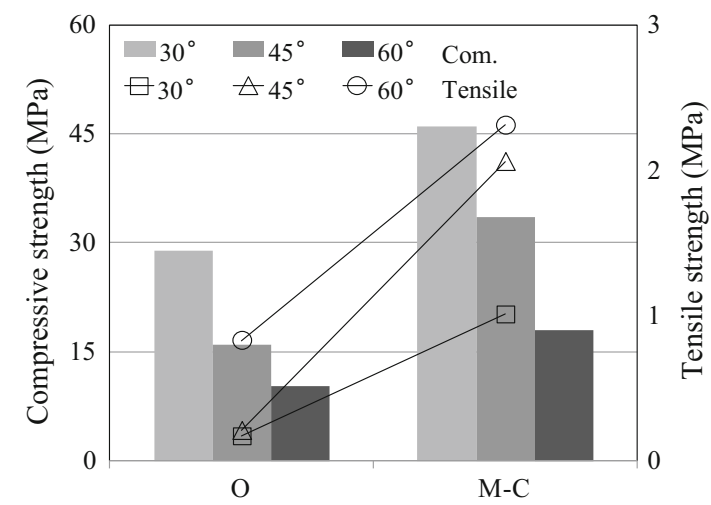

Fig. 7 Compressive- and tensile-shear bond strength.

modification paste and the cement matrix, as shown in Fig. 9. The interface between the modification paste and the cement matrix was determined, as shown in Fig. 9b, and the modification paste and hydration products in the interfacial region were observed, as shown in Fig. 9c and d. It has been shown that the hydration products of calcium hydrate $\left(\mathrm{Ca}(\mathrm{OH})_{2}\right)$ are hydrated to a lesser extent compared to the calcium-silicate-hydrate $(\mathrm{C}-\mathrm{S}-\mathrm{H})$ gel. This suggests that a denser and stronger ITZ with a high level of $\mathrm{C}-\mathrm{S}-\mathrm{H}$ was strengthened by the surface modification.

\section{Effects of Surface Modification on the Mechanical Characteristics of Low- Quality Recycled Aggregates}

In Sect. 3, the results of examining the bonding performance of the simulated concrete fabricated by performing surface modification on crushed stone coarse aggregate and observing the specimens microscopically showed that it was possible to improve the mechanical performance (improvement of ITZ) of concrete through surface modification. Also, based on the results, it is deemed possible to enhance the mechanical performance of concrete and improve the interface enhancement between cement matrix and low-quality recycled coarse aggregate (LRCA) through surface modification (Xiao 2013). Thus, in this section, an experiment was conducted, according to Japanese Industrial Standards (JIS), for the purpose of reviewing the permeability and durability performance (drying shrinkage, neutralization, freezingthawing) and mechanical performance of concrete by examining the effect of surface modification on improving the adhesion quality of recycled aggregate.

\subsection{Materials}

In the experiment, ordinary Portland cement (density: $3.16 \mathrm{~g} / \mathrm{cm}^{3}$; symbol: C) was used as the cement material and land sand (density in saturated surface-dry condition: 2.61 $\mathrm{g} / \mathrm{cm}^{3}$; water absorption ratio: $1.43 \%$; fineness modulus (FM): 2.53; symbol: S) was used as the fine aggregate. The coarse aggregate contained large amounts of recycled aggregates, as shown in Fig. 10b and c, and fell under the category of "Recycled Aggregate L" (hereafter referred to as low-quality recycled coarse aggregate; LRCA) in JIS A 5023. This aggregate was treated with surface modification and the resulting modified aggregate was used. The results of quality of density and water absorption ratio assessment on each type of aggregate showed that the surface modification of low-quality recycled coarse aggregate (LRCA) resulted in increased density and reduced water absorption rate (Table 5). It is considered that the multiple pores in the adhesive paste used in the low-quality recycled coarse aggregate (LRCA) were filled with high-fluidity modification paste, making water penetration more difficult and thereby reducing the absorption rate. Table 5 shows the results of the pre- and post-modification property-test performed on the aggregates, and Table 6 shows the composition of the modification paste. Figure 10 shows the types of recycled aggregates. 


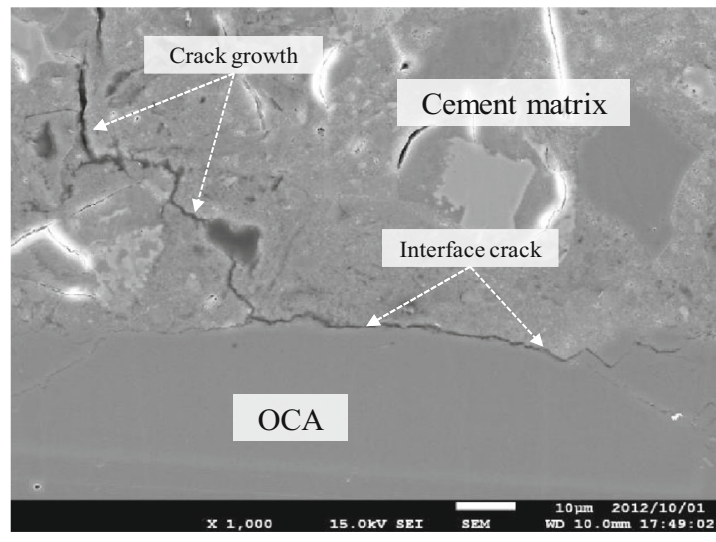

(a)

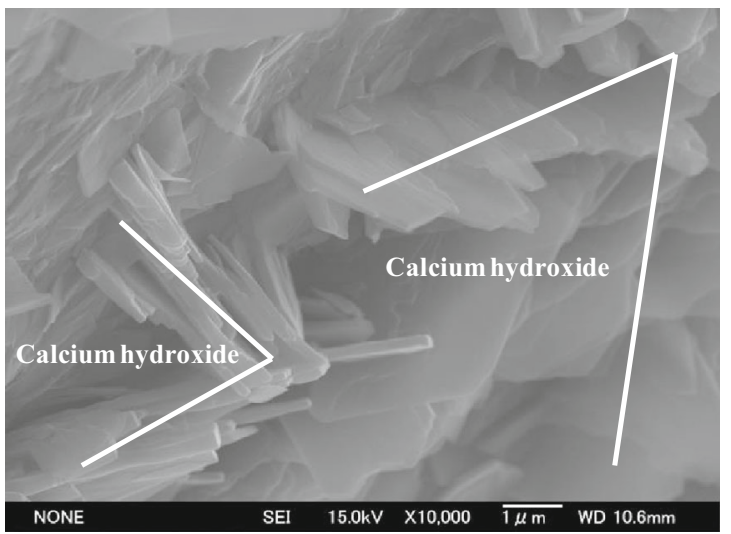

(c)

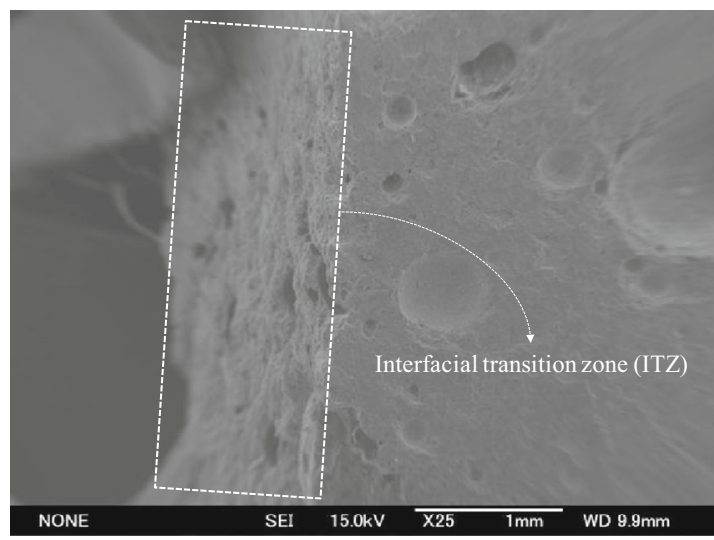

(b)

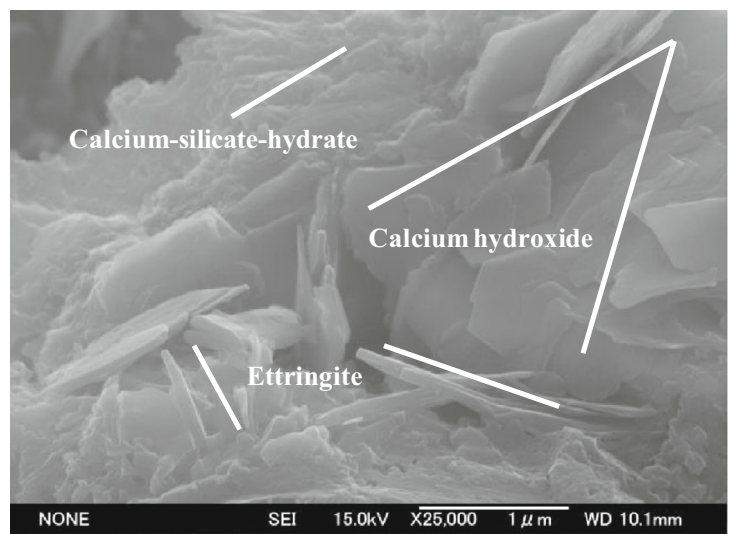

(d)

Fig. 8 Interface of OCA concrete. a Crack of interface. b Interface (ITZ). c Hydration products in interface (ITZ)-1. d Hydration products in interface (ITZ)-2.

\subsection{Composition of Concrete}

In this experiment, the amount of chemical admixture and concrete $\mathrm{W} / \mathrm{C}$ were adjusted so that its performance would be equivalent to that of the low-quality recycled coarse aggregate (LRCA) concrete with W/C of $55 \%$, as shown in Table 7 (Choi et al. 2014a, b). Also, even though concrete generally comprises cement, water, and fine and coarse aggregates, in the case of modified concrete, the amount of cement paste added during modification of the original aggregate must be taken into consideration in the concretemix design. In other words, the amount of cement and water in the modification paste used to coat the low-quality coarse aggregate is considered so that the unit cement volume (in $\mathrm{m}^{3}$ ) would remain constant (Choi et al. 2014a, 2012). In this experiment, the target slump and air content were set at $18 \pm 2.5 \mathrm{~cm}$ and $4.5 \pm 1.5 \%$, respectively, and the results satisfied the target values, as shown in Table 8 .

\subsection{Results and Discussion \\ 4.3.1 Mechanical Characteristics}

Figures 11 and 12 show the results of the experiment on compressive and splitting tensile strength. The compressive strength increased by about $15 \%$ in $\mathrm{M}$ concrete at each material age. The splitting tensile strength increased at a higher rate than the compressive strength, and it increased by $30-35 \%$ higher in $\mathrm{L}$ concrete than in $\mathrm{M}$ concrete. It is considered that this occurred because of the stronger chemical and physical bonds and material densification resulting from the modification paste coated on the interface between the aggregate and cement matrix of L concrete. In addition, the fracture plane of the concrete specimens was examined following the splitting-tensile-strength test to determine the bonding performance of each concrete specimen; the results are shown in Figs. 13 and 14. Fractures were observed at the aggregate interface in many areas of $\mathrm{L}$ concrete, but in the case of $\mathrm{M}$ concrete, the majority of the cracks caused by loading occurred in a through pattern.

\subsubsection{Permeability}

The modification treatment of the surface of adhesive paste consist of a porous causes densification on the surface of recycled coarse aggregates, resulting in higher density and lower absorption ratio compared to low-quality recycled aggregates as shown in Sect. 4.1. On the other hand, large amounts of adhesive paste are present in the low-quality recycled coarse aggregates (Fig. 10) and modified aggregates used in this study, and due to the large sizes of internal pores compared to general coarse aggregates, there may be an increased possibility of penetration of water and harmful substances into the concrete from the external environment. In other words, the progressive penetration of deterioration factors such as water, $\mathrm{CO}_{2}$ gas and chloride ions $\left(\mathrm{Cl}^{-}\right)$into the concrete increases permeability, which is highly associated with durability. This in turn accelerates deterioration of 


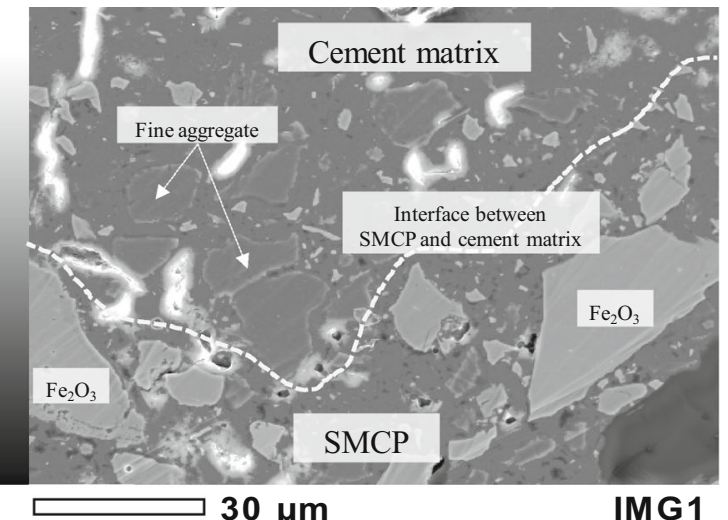

(a)

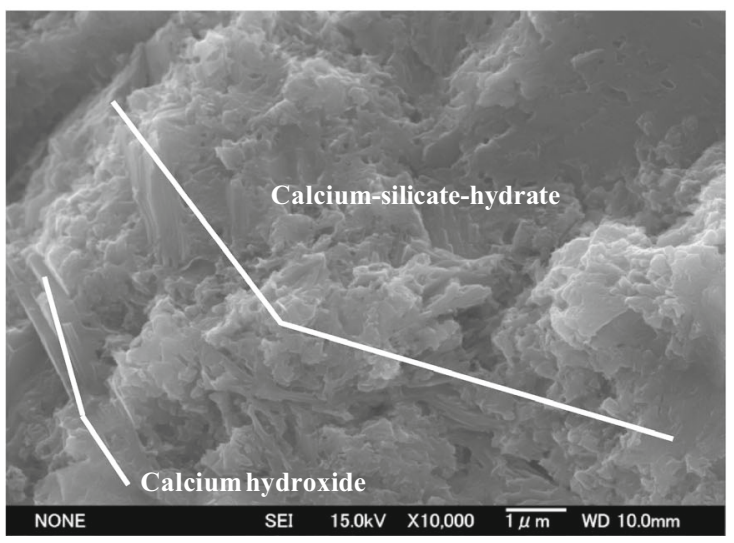

(c)

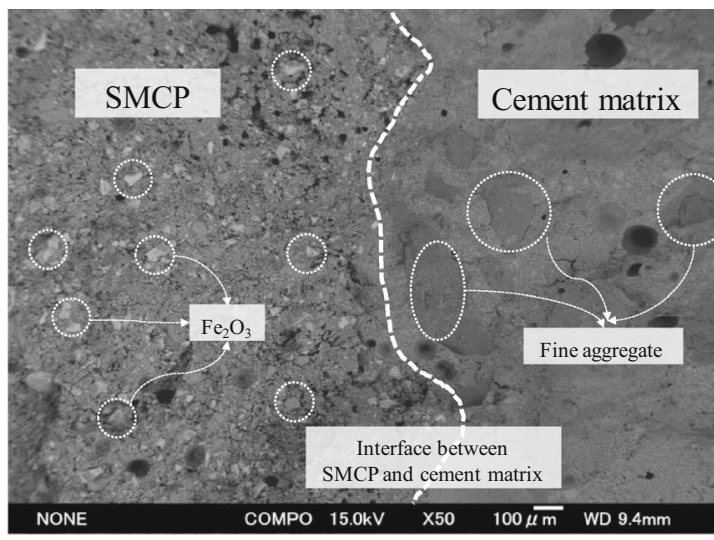

(b)

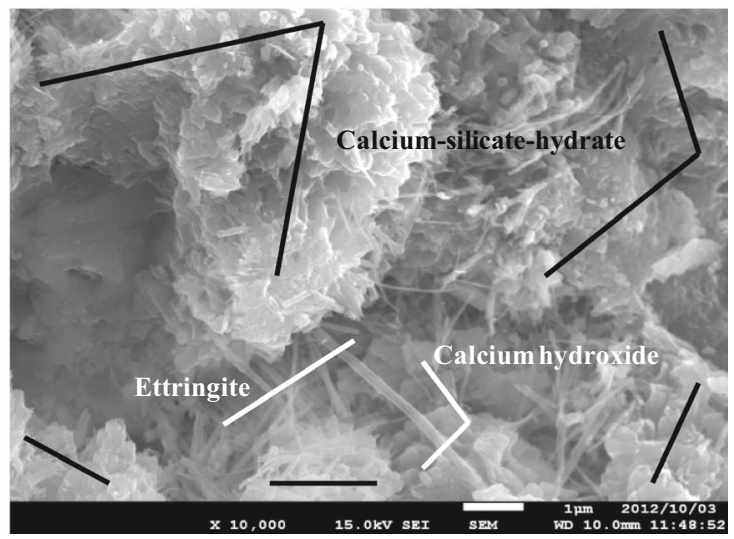

(d)

Fig. 9 Interface of SMCA concrete. a Interface 1. b Interface 2. c Hydration products in interface 1. d Hydration products in interface 2.

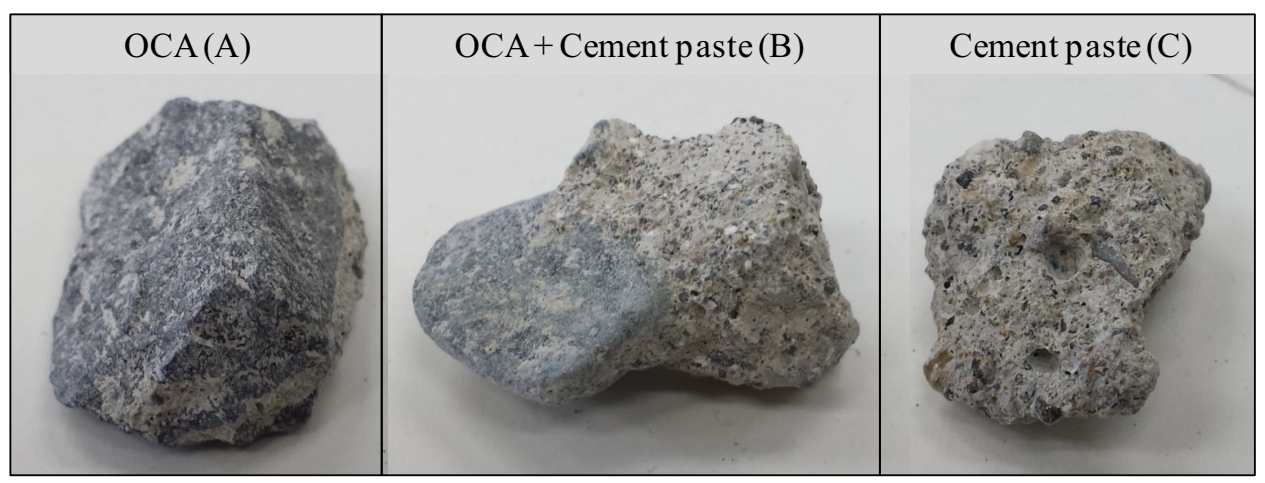

Fig. 10 Types of recycled coarse aggregates.

Table 5 Type and quality of coarse aggregates.

\begin{tabular}{c|c|c}
\hline Type & Standard density $\left(\mathrm{g} / \mathrm{cm}^{3}\right)$ & Water absorption ratio $(\%)$ \\
\hline \hline$L$ & 2.42 & 7.57 \\
\hline$M$ & 2.49 & 6.89 \\
\hline
\end{tabular}

$L$ low-quality recycled coarse aggregate, $M$ modified coarse aggregate.

Table 6 Composition of modification paste (based on $1 \mathrm{~kg}$ of original coarse aggregates) (Choi et al. 2014a).

\begin{tabular}{c|c|c|c|c|c}
\hline W/C $(\%)$ & Water $(\mathrm{g})$ & Cement $(\mathrm{g})$ & $\mathrm{Fe}_{2} \mathrm{O}_{3}(\%)$ & Admixture $(\%)$ & Table flow $(\mathrm{mm})$ \\
\hline \hline 30 & 21 & 70 & $\mathrm{C} \times 100$ & $\mathrm{C} \times 1.9\left(b^{*}\right)$ & 300 \\
\hline
\end{tabular}

$b^{*}$ superplasticizer. 
Table 7 Composition of concrete.

\begin{tabular}{|c|c|c|c|c|c|c|c|c|c|}
\hline \multirow[t]{2}{*}{ Type } & \multirow[t]{2}{*}{$\mathrm{W} / \mathrm{C}(\%)$} & \multirow[t]{2}{*}{ Slump (mm) } & \multirow[t]{2}{*}{ Air (\%) } & \multirow[t]{2}{*}{$\mathrm{G}_{\max }(\mathrm{mm})$} & \multicolumn{4}{|c|}{ Unit weight $\left(\mathrm{kg} / \mathrm{m}^{3}\right)$} & \multirow{2}{*}{$\begin{array}{c}\text { Admixture } \\
(\%) \\
\end{array}$} \\
\hline & & & & & $\mathrm{W}$ & $\mathrm{C}$ & $\mathrm{S}$ & $\mathrm{G}$ & \\
\hline$L$ concrete & \multirow[t]{2}{*}{55} & \multirow[t]{2}{*}{$180 \pm 25$} & \multirow[t]{2}{*}{$4.5 \pm 1.5$} & \multirow[t]{2}{*}{20} & 175 & 318 & 805 & 913 & $\mathrm{C} \times 0.5\left(a^{*}\right)$ \\
\hline$M$ concrete & & & & & 172 & 312 & 805 & 915 & $\mathrm{C} \times 0.5\left(a^{*}\right)$ \\
\hline
\end{tabular}

$L$ concrete low-quality recycled coarse aggregate concrete, $M$ concrete modified coarse aggregate concrete, $a^{*}$ air entraining agent.

Table 8 Slump and air content of each type of concrete.

\begin{tabular}{c|c|c}
\hline Type & Slump $(\mathrm{cm})$ & Air content (\%) \\
\hline \hline L concrete & 17.2 & 4.6 \\
\hline M concrete & 18.3 & 4.0 \\
\hline
\end{tabular}

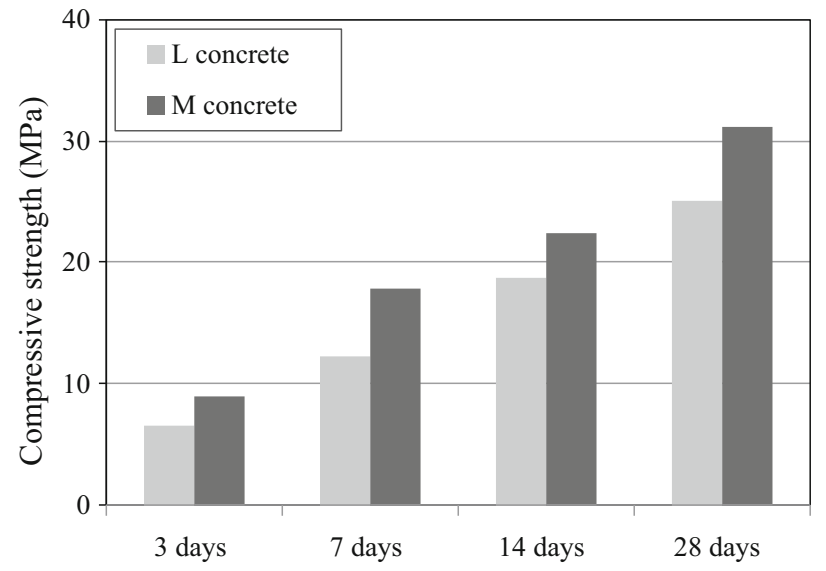

Fig. 11 Compressive strength.

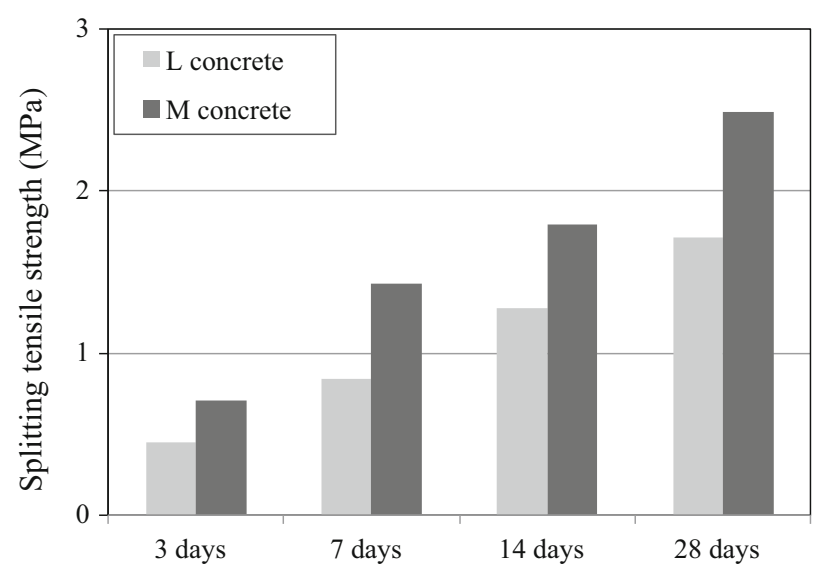

Fig. 12 Splitting tensile strength.

concrete and as a consequence, there are concerns of fatal damage to the concrete structure concerned (Jacobsen 1996; Wang et al. 1997; Khatri and Sirivivatnanon 1997). Accordingly, after fabricating concrete using low-quality recycled coarse aggregates and modified coarse aggregates, the water and air permeability coefficients of each specimen were measured and the correlations between the water and air permeability coefficients and compressive strength were analyzed as a means to determine the water tightness and air tightness of each concrete specimen.

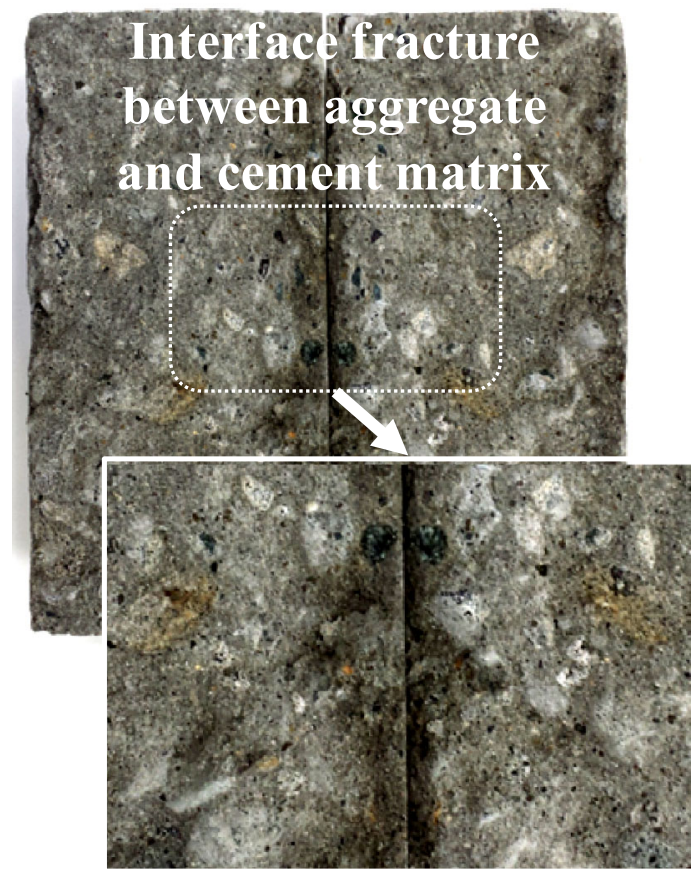

Fig. 13 Fracture surface of $L$ concrete.

The results of the experiment on water permeability showed that the water permeability coefficient of the $M$ concrete was $0.87 \times 10^{-9} \mathrm{~m} / \mathrm{s}$, as shown in Fig. 15., indicating that its water permeability resistance was 3.9 times higher than that of the L concrete, the water permeability coefficient of which was measured to be $3.41 \times 10^{-9} \mathrm{~m} / \mathrm{s}$. Also, the results of the experiment on air permeability showed that the air permeability coefficient of the $\mathrm{M}$ concrete was $2.26 \times 10^{-9} \mathrm{~m} / \mathrm{s}$, indicating that its air permeability resistance was 4.2 times higher than that of the $\mathrm{L}$ concrete, the air permeability coefficient of which was measured to be $3.41 \times 10^{-9} \mathrm{~m} / \mathrm{s}$. This was similar to the results of the water permeability experiment (Fig. 15). In addition, as for the correlations between the water and air permeability coefficients and compressive strength, Fig. 16 shows that the higher the strength of the $M$ concrete resulting from the modification treatment of the surface of low-quality recycled aggregates using an inorganic material 


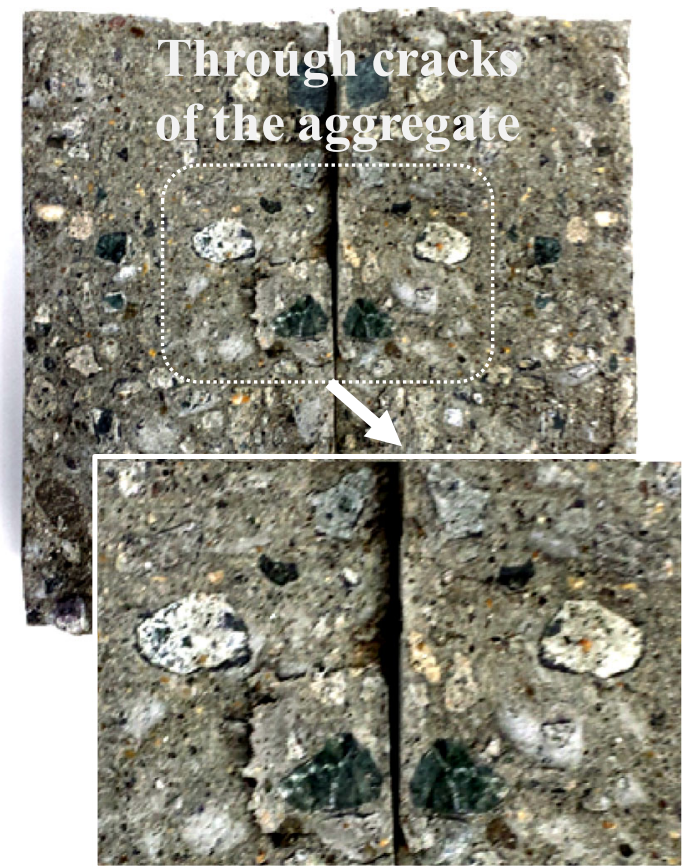

Fig. 14 Fracture surface of $\mathrm{M}$ concrete.

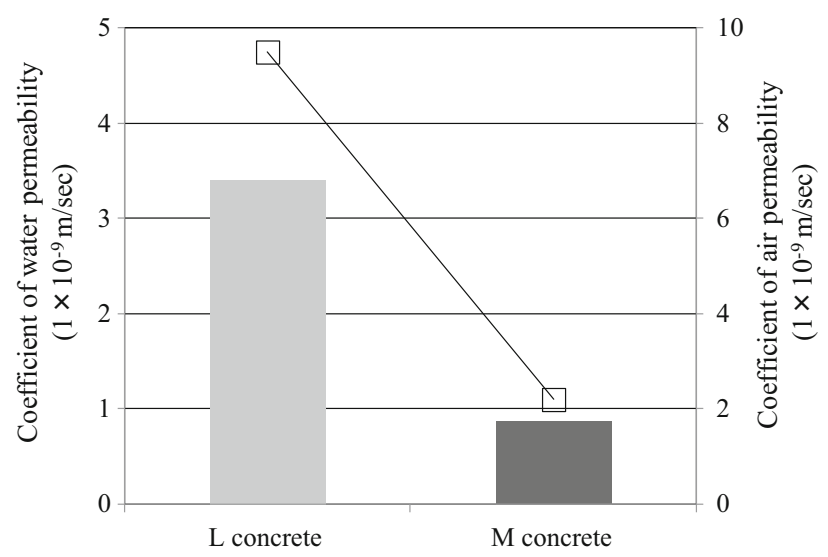

Fig. 15 Coefficient of permeability of each specimen.

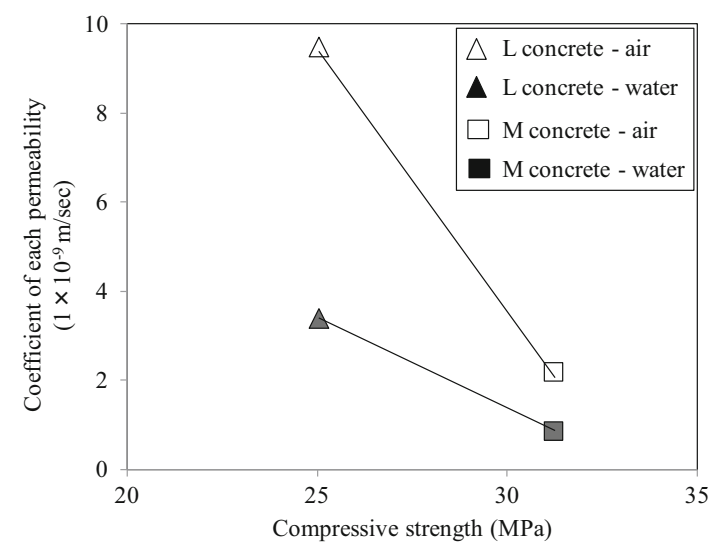

Fig. 16 Correlation between each permeability and compressive strength.

(Sect. 4.3.1), the higher the water and air permeability resistances were (Hilsdorf and Kropp 1995). In other words, modification treatment of the porous adhesive paste surface
(Fig. 10) caused densification in the surface of the recycled coarse aggregates and improvement of the interfacial adhesive performance between the low-quality recycled coarse aggregates and the cement matrix within the concrete. Based on this, when this is applied to an actual structure made of modified aggregate concrete, it will effectively improve its strength and inhibit the penetration of deterioration factors. Figure 17 shows the cross-sections of low-quality recycled coarse aggregate concrete (L concrete) and modified aggregate concrete ( $\mathrm{M}$ concrete). In the case of $\mathrm{L}$ concrete shown in Fig. $17 \mathrm{a}$, the interface between the porous adhesive paste and the cement matrix is not well-defined, and it is expected that the area with the porous adhesive paste will become a penetration route for deterioration factors from the external environment. However, in the case of $M$ concrete in Fig. $17 \mathrm{~b}$, the interface between the porous adhesive paste and the cement matrix has become clearly defined as a result of the modification treatment of low-quality recycled aggregate surface, and the densification in the interface is expected to effectively inhibit the penetration of deterioration factors.

\subsubsection{Durability}

Both L concrete and $\mathrm{M}$ concrete, whose surface was coated, exhibited a high water-absorption rate of about $7 \%$. Aggregates with a high absorption rate can have a significant negative impact on concrete properties and durability. Thus, in order to review the durability performance of each concrete specimen, the resistance against drying shrinkage, neutralization, and freezing-thawing was reviewed. The results are shown in Figs. 18, 19 and 20. Figure 18 shows the results of the drying-shrinkage test. The specimens were removed from the formwork at day 1 , and water cured until day 7. After that, the drying-shrinkage deformation was observed at a constant temperature of $20{ }^{\circ} \mathrm{C}$ and a humidity level of $60 \%$ RH. Substantial differences were observed in the concrete specimens starting at week 1 , and the dryingshrinkage rate was lower in $M$ concrete by $10-20 \%$ compared to $\mathrm{L}$ concrete between week 4 and week 6 . Based on these results, it is considered that moisture evaporation in the coarse aggregates was suppressed somewhat because the SMCP was added to the cement, and the micro-filler effect and accelerated hydration reaction caused the ITZ structure to grow denser. Figure 19 shows the results of the freezing-thawing experiment. The difference in the relative elastic modulus between L concrete and $\mathrm{M}$ concrete was small for the first 150 cycles. After 150 cycles, however, the difference gradually increased, and the modulus of elasticity was lower in $\mathrm{M}$ concrete than L concrete by about $7 \%$ at the end of 300 cycles. Generally, in the case of aggregates with high water absorption rate, there is a larger volume of water that can freeze inside the concrete, which means concrete deterioration resulting from freezing and thawing is likely to occur. For L concrete, the resistance against freezing and thawing was improved as the surface modification reduced the absorption rate of the aggregate and at the same time, the material was densified as a result of the improved 


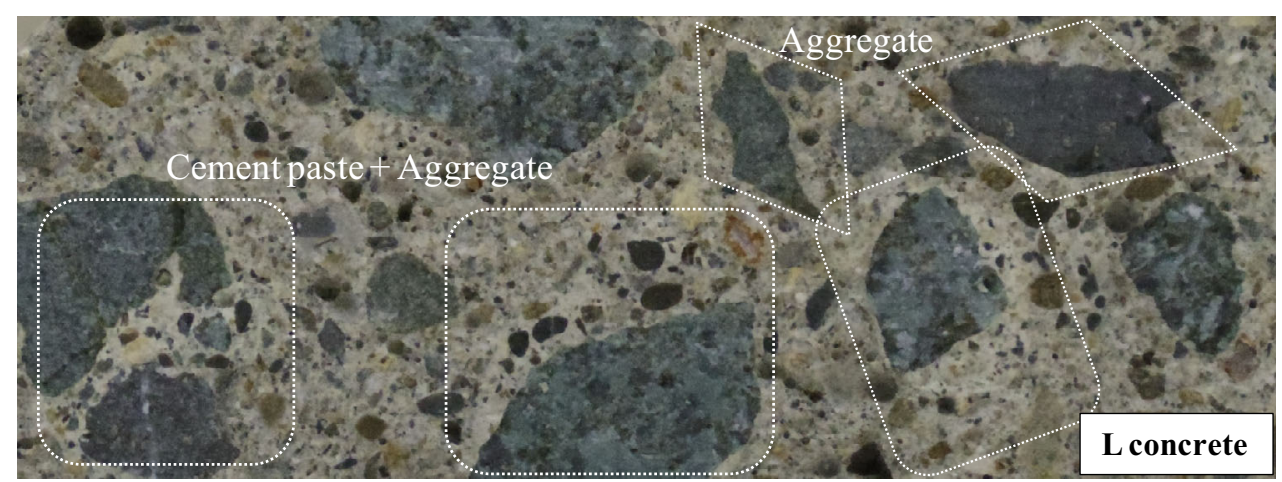

(a)

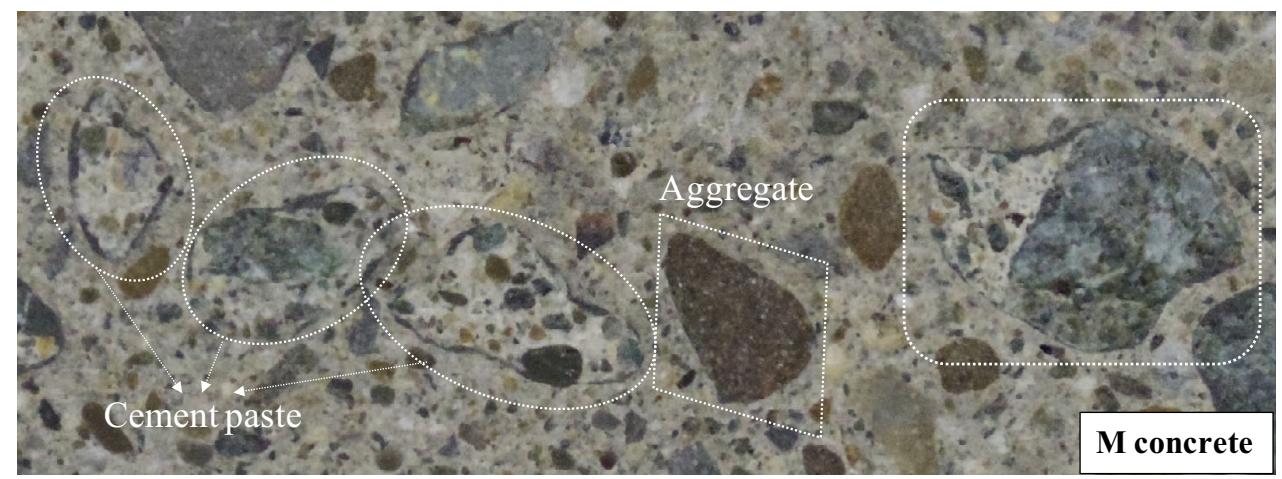

(b)

Fig. 17 Cutting section of each concrete. a $L$ concrete. b $M$ concrete.

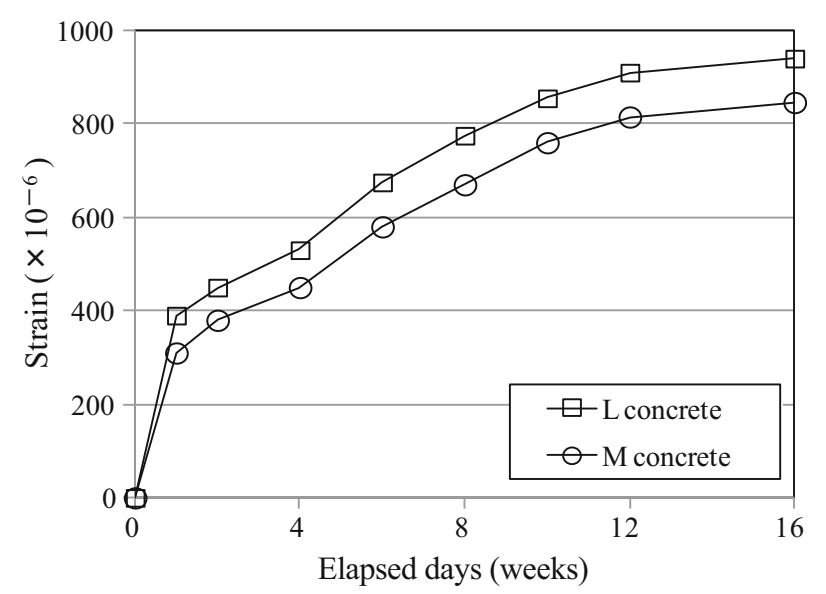

Fig. 18 Drying shrinkage.

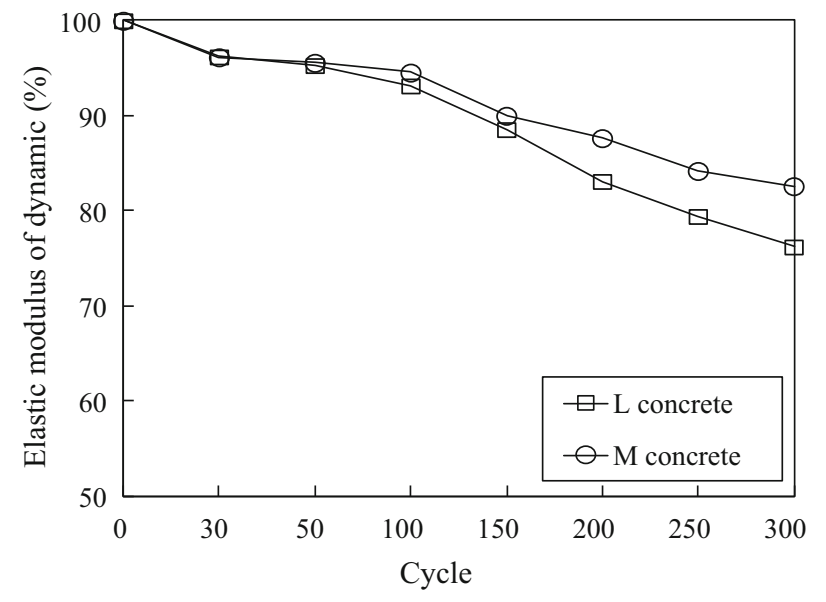

Fig. 19 Freezing and thawing.

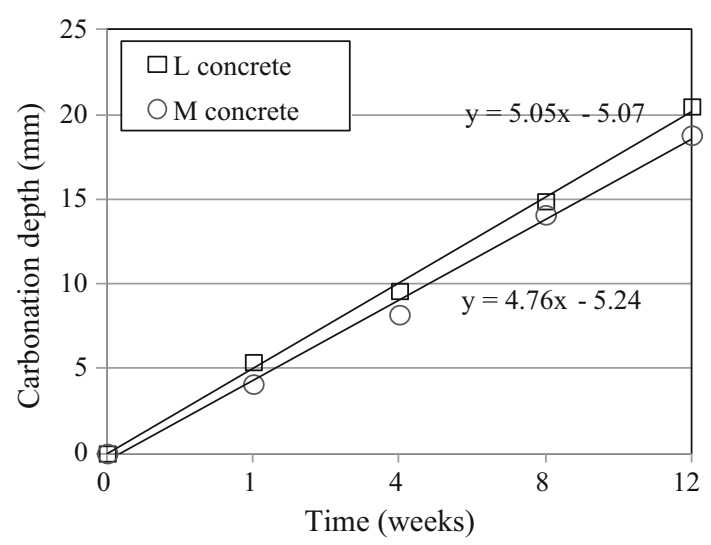

Fig. 20 Carbonation depth.

performance of the aggregate surface. In addition, based on the proportional relationship between the water absorption ratio and the carbonation rate coefficient (Nagataki et al. 2000), it was initially speculated that there was a possibility that $\mathrm{M}$ concrete, with a slightly lower water absorption ratio than the $\mathrm{L}$ concrete, could exert a negative impact on the concrete properties as it would facilitate the movement of substances within the concrete. As shown in Fig. 20, the carbonation depth in $\mathrm{M}$ concrete was decreased by approximately $3-5 \%$ at weeks $1,4,8$ and 12 , compared to $\mathrm{L}$ concrete. Based on this result, it is difficult to argue that there was a substantial difference in terms of carbonation resistance and that the quality of the density and water absorption ratios of $M$ concrete was sufficient in this regard. 


\section{Results and Discussion}

The following conclusions were made based on the results of the experiments conducted to examine the interface enhancement between cement matrix and coarse aggregate of low-quality recycled coarse aggregates with surface modification.

(1) When the $\mathrm{W} / \mathrm{C}$ ratio was $55 \%$, the improvements in the shear bond strength were confirmed to be due to the SMCP coating, and the ITZ was densified by the admixtures (inorganic materials). The FE-SEM results confirmed that the interface between the SMCA and the cement matrix was denser and ITZ was strengthened with a high level of calcium-silicate-hydrate by the surface modification.

(2) The use of low-quality recycled coarse aggregates (LRCA), the surfaces of which were modified with inorganic materials, resulted in improved strength, permeability, and durability of concrete. These improvements are thought to be due to the enhanced adhesion between recycled coarse aggregate and cement matrices resulting from the improved ITZ that existed in the interface between the coarse aggregate and the cement matrix.

\section{Open Access}

This article is distributed under the terms of the Creative Commons Attribution 4.0 International License (http:// creativecommons.org/licenses/by/4.0/), which permits unrestricted use, distribution, and reproduction in any medium, provided you give appropriate credit to the original author(s) and the source, provide a link to the Creative Commons license, and indicate if changes were made.

\section{References}

Choi, H. S., Kitagaki, R., \& Noguchi, T. (2012). A study on the completely recovery of surface modification aggregate using microwave and effective utilization. In Proceedings of the 5th ACF international conference, Pattaya, Thailand, October 2012, Session 1-2, ACF2012-0093 (pp. 41-46).

Choi, H. S., Kitagaki, R., \& Noguchi, T. (2014a). Effective recycling of surface modification aggregate using microwave heating. Journal of Advanced Concrete Technology, $12,34-45$.

Choi, H. S., Kitagaki, R., \& Noguchi, T. (2014b). Using microwave heating to completely recycle concrete. Journal of Environmental Protection, 5, 583-596.
Hendriks, C. H. F., \& Janssen, G. M. T. (2001). Construction and demolition waste-General process. HERON, 46, $79-88$.

Hilsdorf, H. K., \& Kropp, J. (1995). Performance criteria for durability, RILEM Report 12, London, UK, pp. 166-178.

Jacobsen, S. (1996). Effect of cracking and healing on chloride transport in OPC concrete. Cement and Concrete Research, 26(6), 869-881.

Khatri, R. P., \& Sirivivatnanon, V. (1997). Role of permeability in sulfate attack. Cement and Concrete Research, 27(8), 1179-1189.

Kumar Mehta, P., \& Moneiro, P. J. M. (2006). Concrete-Microstructure, Properties and Materials. New York, NY: McGraw-Hill Companies.

Nagataki, S., Gokce, A., \& Saeki, T. (2000). Effects of recycled aggregate characteristics on performance parameters of recycled aggregate concrete. American Concrete Institute, ACI Special Publication, 52, 462-467.

Noguchi, T. (2008). Resource recycling in concrete: Present and future. Stock Management for Sustainable Urban Regeneration, 4, 255-274.

Noguchi, T., \& Tamura, M. (2001). Concrete design towards complete recycling. Structural Concrete Journal of the fib, 2, 155-167.

Shima, H., Tateyashiki, H., Matsuhashi, R., \& Yoshida, Y. (2005). An advanced concrete recycling technology and its applicability assessment through input-output analysis. Journal of Advanced Concrete Technology, 3, 53-67.

Tazawa, E. (2002). Concrete engineering (p. 127). Tokyo, Japan: Asakura Publication.

Tsujino, M., Noguchi, T., Tamura, M., Kanematsu, M., \& Maruyama, I. (2007). Application of conventionally recycled coarse aggregate to concrete structure by surface modification treatment. Journal of Advanced Concrete Technology, 5, 13-25. doi:10.3151/jact.5.13.

Tsujino, M., Noguchi, T., Kitagaki, R., \& Nagai, H. (2010). Completely recyclable concrete of aggregate-recovery type by a new technique using aggregate coating. Architectural Institute of Japan, 75(647), 17-24. (in Japanese).

Tsujino, M., Noguchi, T., Kitagaki, R., \& Nagai, H. (2011). Completely recyclable concrete of aggregate-recovery type by using microwave heating. Architectural Institute of Japan, 76(660), 223-229. (in Japanese).

Um, T. S., \& Choi, S. H. (1997). The effect of the mineralogical features of aggregates in the bonding force and workability of the concrete. Journal of the Korea Concrete Institute, 9(5), 207-216. (in Korean).

Wang, K., Jansen, D. C., \& Shah, S. P. (1997). Permeability study of cracked concrete. Cement and Concrete Research, 27(3), 381-393.

Xiao, J. (2013). Properties of interfacial transition zones in recycled aggregate concrete tested by nanoindentation. Cement and Concrete Research, 37(3), 276-292. 